\title{
“DISASTER RESILIENT SOCIETY WITH YOUTH” PROJECT OF THE CIVIL DEFENCE ORGANIZATION AIMING DISASTER RISKS REDUCTION
}

\author{
Y. Eker ${ }^{1}$, M.Yılmabaşar ${ }^{1}$
}

${ }^{1}$ Civil Defence Organization, Operation and Training Department, TRNC- uacyprus@gmail.com

KEY WORDS: Disaster, Resilience, Risks Reduction, Voluntarism, Youth

\begin{abstract}
:
The loss of lives, injuries and the damage on economies that occur as a result of disasters is increasing due to the changing nature. People need to adopt themselves to be able to resist against disasters. Nevertheless, minimizing the costs of disasters can achieved not individually but rather by a well-organized social system. This requires a decentralized disaster management system that would allow participation of not only central authorities but also widespread volunteers. Also, pre-emptive cautions to raise public awareness and capabilities about how to struggle against disasters are very important component of being well organized. Turkish Republic of Northern Cyprus (TRNC) Civil Defence Organization has constituted the "Disaster Resilient Society with Youth Project" to reduce number of loss of life, injuries and economic loss as global targets envisaged in Sendai Framework for Action. This project is being implemented in line with the objects of Sendai Framework for Disaster Risk Reduction which is inspired from the principle of "Disaster risk reduction requires an all-of-society engagement and partnership. While the project is managed by Civil Defence Organization, it is implemented by the participation of volunteers. The project is the last phase of a series of projects which have been realized for 35 years in line with the same goal of reducing loss of lives, injuries and economic loss while various concepts targeted to address different levels of the society. The objective of the Project is to firstly choose some individuals and then train them to have disaster consciousness and awareness about disaster management cycle in society. These people would potentially provide support to responding official teams in case of an unexpected disaster. For this reason, the project also involves practical training and practices as complementary to the theoretical education phase. In the first place, a four year road map is determined to improve the project by identifying disruptions and weaknesses compared to similar projects around the world. The establishment of target groups of the Project within youth is important not only to improve the effectiveness of responding phase, but also to maintain a sustainable system for the progression of the Project. In order to encourage and increase the participation of volunteers to the Project, it is planned to issue certificates, badges and prize for those who would be successful during the training phase. In order to achieve the goals of the Project, the project managers seek collaboration of universities, local authorities, central authorities and nongovernmental organizations which are seen as stakeholders.
\end{abstract}

\section{INTRODUCTION}

An effective struggle against disasters requires pre-emptive cautions that are taken without waiting the disasters to happen and invokes widespread participation of public to decentralize the struggle. Disasters are the reality of the world which we need to learn how to live together with. By accepting the fact that we cannot eliminate all consequences of disasters, it is possible to minimize loss of life, injuries and negative effects on economies. At that point the phenomenon of resilience is a good point to start. Resilience, according to Hyogo Framework for Action, is "the capacity of a system, community or society potentially exposed to hazards to adapt, by resisting or changing in order to reach and maintain an acceptable level of functioning and structure. This is determined by the degree to which the social system is capable of organizing itself to increase this capacity for learning from past disasters for better future protection and to improve risk reduction measures. (UN/ISDR, 2004)"

In the given definition, there are some keywords such as "system, community or society" which deserve a closer attention in order to create a "disaster resilient society". For this aim, people from all levels of the society such as children, youth, students, retired people etc. together with public and private organizations, institutions and NGO's should be encouraged to engage in disaster management cycle. There are lots of works to be done without waiting a disaster to hit a country, but as a caution before the disaster takes place. In Sendai Framework for Action, four priorities are listed in order to reduce disaster risks and strengthen resilience;

1. Understanding disaster risk,

2. Strengthening disaster risk governance to manage disaster risk,

3. Investing in disaster risk reduction for resilience,

4. Enhancing disaster preparedness for effective response and to "Build Back Better" in recovery, rehabilitation and reconstruction.(UNISDR 2015)

This article aims to examines the need of the society in becoming more "resilient" to the disasters and emergencies in TRNC. It investigates the Disaster Resilient Society With Youth Project, of the Civil Defence Organization, in which there are modern disaster management cycle phases such as mitigation, preparedness, response and recovery Thus, the following chapter investigates the past disasters to find out how the need for this type of projects of emerged. The modern disaster management systems aim not only to respond to disasters but also to take pre-emptive actions by which actions to train society with the ability of resisting to disasters before 
they take place. Then, the third chapter particularly illustrates some of the disasters experienced in TRNC to highlight what was lacking in the struggle against these disasters. The fourth chapter emphasizes the components of the project by exploring the aims and the role of Civil Defence Organization in the process of creating disaster resilient society, which is another important subject of this paper. While focusing on this subject, activities held by Civil Defence Organization together with important stakeholders such as International Universities Search and Rescue Council, in line with creating a disaster resilient society will also be mentioned briefly.

\section{BACKGROUND}

The results of disasters might be devastating in some cases. The Tohoku, Japan earthquake on March 11, 2011, caused 180.000 death or missing person while the total estimated loss by this earthquake would be more than 200 billion US dollars (H.Kawase, 2014). Hurricane Katrine in 2005 hit the Gulf Coast region of the United States and caused death of more than 1.800 people. Examples can be multiplied for not only nature based disasters but also manmade disasters such as the explosion at the Chernobyl Nuclear Power Plant on April 26, 1986. This accidental explosion caused a large scale of damages in terms of deaths, injuries and economic loss by which their effects extend to this today.

Kadığlu (2011) points out that the modern disaster management system begun to evolve 1950's when civil defence plans started. Its evolution followed by flood insurances in 1960's, plans intended for responding disasters, national responding plans, corporate cooperation plans, national responding support plans and finally disaster management framework agreements (Kadığlu 2011). Strategies to reduce the risks of disasters were shaped accordingly to the conclusions of the 1994 World Conference on Natural Disaster Reduction which was held at Yokohama city of Japan. The conference produced the outcome of "Yokohama Strategy Plan of Action for a Safer World: Guidelines for Natural Disaster Prevention, Preparedness and Mitigation". Yokohama Strategy followed by "Hyogo Framework for Action 2005-2015" and finally "Sendai Framework for Disaster Risk Reduction 2015-2030". As mentioned above, to adapt international framework agreements, state authorities must have their national disaster management systems to consider the priorities stated in Sendai Framework. In this sense, the first precaution for a national disaster management authority would be to identify the risks of disaster in that country. Major disasters given above, enforce states to modify their own disaster management system by considering the risks of disasters and focusing on disaster risk reduction phase to create resilience. While taking all these cautions, states also consider the fact that in order to determine sustainable development; they should avoid destructive effects of disasters.

During the process of creating a disaster resilient society, it is important for public and private institutions to have the capacity to work in coordination. In addition, role of the society should not be ignored during this process. A disaster management system excluding any level of the society will not function properly. In fact, if a disaster management system aims to protect human life and property against the effects of a disaster, the most important and meaningful act will be to educate and train all levels of that society about how to behave or not to behave when a disaster is encountered. These components of modern disaster management system aiming resilience are the basic principles of Japan International Cooperation Agency (JICA). JICA emphasizes the need for a disaster resilient society, by which government prioritized disaster risk reduction in the country's policy, disaster risk reduction is incorporated into development plans and programs in all sectors and fields, and government provides prior investment in disaster risk reduction (JICA 2017).

In the TRNC, there is a disaster management authority under the Prime Ministry called "Disaster and Emergency Management Committee" which includes private sector institutions as well as public authority. Under this system, Civil Defence Organization has an important role, as a coordinator member, to ensure the cooperation between members of the committee.

TRNC Civil Defence Organization organizes educations, trainings and exercises under the title of "Public Organization" that target participants between the ages of $48-60$, to students from pre-schools, primary schools, secondary schools, high schools and universities. The focal point of these activities is the importance of disaster management cycle and creation of a disaster resilient society that can avoid the negative effects of disasters and emergencies. In coordination with Ministry of Education and Culture, Civil Defence Organization organizes activities with the purpose of creating disaster awareness of primary and secondary school students. These activities include providing trainings for first aid and fire extinguishing, performing drills on how to act during disasters, and supporting social responsibility projects by organizing competitions in poetry, art, written composition, poster, short film and photograph.

Another key role of the Civil Defence Organization is its support to the International Universities Search and Rescue Council (IUSARC) ${ }^{1}$. Through the initiative of Civil Defence Organization and universities active in North Cyprus, IUSARC was founded in April 2012 by participation of 30 universities from 20 countries. The purpose of forming this organization was to provide university youth with the opportunities to operate internationally in the fields of civil defence, search \& rescue and humanitarian aid. As of 2018, IUSARC has 44 member universities from 22 countries all around the world . Since 2012, representative of member universities have been invited to our country through programs organized by IUSARC, and on April and May of each year, trainings, seminars and drills are performed. In cooperation with IUSARC, Civil Defence Organization carries out " 13 October UN World Disaster Risk Reduction Day", "Week of Social Responsibility", "22 March World Water Day" activities and "IUSARGames Search \& Rescue Games" every year at international level.

In 2016, IUSARGames Search \& Rescue Games was carried out by the organization with the participation of search \& rescue team club member students from member universities. IUSARGames have a distinct importance for being a unique organization with search and rescue theme in international level and across the universities. The IUSARGames are organized with the aim to;

* ensure that university students become a potential factor in Search \& Rescue activities by improving

\footnotetext{
${ }^{1}$ For more information please visit www.iusarc.org
} 
their skills and motivations in Search \& Rescue activities,

* popularize the activities of International Universities Search and Rescue Council (IUSARC) in international arena,

* announce IUSARC's activity within international arena and bring in new members to the Council,

* ensure that Search \& Rescue games event receives worldwide recognition and performed at a more professional level in future years,

* contribute to world peace through the games performed with the participation of youth from various countries.

The last phase of activities of the TRNC Civil Defence Organizations, organized with the aim of creating a disaster resilient society, will be the "Disaster Resilient Society with Youth" project.

\section{DISASTER RISKS IN TRNC}

As an island in the Mediterranean Sea, Cyprus has a hot climate which has become further hot under the influence of global warming. Especially during summer time, forest fires are frequently observed. In the fire in Beşparmak in 1995, which has been the most devastating fire in the country, a total amount of 8069 hectares of land including 5803 hectares of forest area and 2266 hectares of agricultural land were burnt. This amount was $9.52 \%$ of the total forest area of TRNC at that period. (Ali Küçükosmanoğlu 2003) The strong winds during fire increased the challenges to tackle with it. In another fire disaster that occurred in 1998, a total area of 3700 hectares, including 2742 hectares of forest area and 958 hectares of private land was burned in Güzelyurt. (Ali Küçükosmanoğlu 2003) This loss of forests amounted to $4,50 \%$ of total forest area of TRNC.

Also, there were flood events that caused severe damages on homes or land of many people. In January, 2010 Güzelyurt district witnessed a destructive flood in which, luckily, no loss of life were experienced while there was a huge economic loss. During the flood, 170 workplaces and 230 houses were damaged and government paid an amount of one million TL as compensation. At the core of the flood problems was the lack of a strong infrastructure to control rain water. This lack of infrastructure, to control and keep rain water, lead to drought due to the insufficient water resources as a major disaster risk in TRNC. According to the General Agricultural Insurance Fund of TRNC, the amount of land affected by drought in our country in 2016 was 756,000 acres, while the amount paid to producers by the Agricultural Insurance Fund amounted to 66 million TL. These figures clearly demonstrate the extent to which the drought has damaged the country's economy.

Moreover, Cyprus is located in the Alpine-Himalayan seismic zone which includes countries such as Spain, Tunisia, Algeria, Morocco, France Italy, Greece, Turkey, Iran, Azerbaijan, Afghanistan, Pakistan and India, in which about $15 \%$ of the world earthquakes occur (Macao Meteorological and Geophysical Bureau 2014). This leads to the fact that TRNC is always under the risk of a destructive earthquake and its consequences.

Beside the nature based disasters, TRNC also faces manmade risks. With developments in technology, industrial areas, institutions working with chemical, biological and radiological possess risks to cause disaster. On the other hand, considering the geopolitical position of the Cyprus, the risk of a war cannot be ignored. The emergence of transnational terrorist groups in Middle East and their capabilities is an important threat for TRNC as well as other states in the region. ISIS has capability to engage bombs to drones and send them to Cyprus as retaliation in case of the use of British bases by the US or the UK to bomb them. Or, a chemical fire in Syria might easily affect TRNC.

Disaster management system firstly formed in 1983 with the establishment of the TRNC, to struggle with earthquakes, fires and epidemic diseases as disasters and emergencies. At that time, when the disaster management system was formed, all types of disaster and emergency risks had not been considered comprehensively. In addition, the system was based on only reactively responding to a disaster after it takes place. In 2013, a new system established for disaster management in TRNC, called "Crisis Management Committee", by which the scope of the disaster was widened. But still, the system was focusing on crisis management, meaning that taking necessary measures only after a disaster occurs, not before the disaster coming. No pre-emptive actions were considered.

With the initiative of Civil Defence Organization in 2016 to address these deficits of the crisis management system, Crisis Management Committee has been replaced by "Prime Ministry Disaster and Emergency Management Committee". This initiative was realized in line with the principle of modern, integrated disaster management system considering all phases of disaster management cycle such as mitigation, preparedness, response and recovery. The Committee is headed by Prime Ministry of the TRNC, with the members of ministries including the Ministry of Health, Ministry of Interior, Ministry of Foreign Affairs, Ministry of Agriculture and Transportation. In addition, Security Forces, Police Department, Fire Department, Forestry Department and Civil Defence Organization are also actively involved as the members of the committee. The Committee plans, coordinates and supervises measures that must be taken for risk reduction, capabilities and capacity of responding institutions such as Civil Defence Organization. As an important component of the system, Civil Defence Organization is actively involved not only in response, but also mitigation and preparedness phases of the cycle. In other words, it also considers pre-emptive actions.

As experienced in 1995 fire and 2010 flood, previous disaster management systems was lacking of pre-emptive actions, focusing on promotion of responding capabilities. This invokes to formulate and implement projects in which an important level of the society will be educated and trained against disaster risks, ensuring that they will have consciousness about disasters, resilience and modern disaster management cycle. The past experiences of disasters both in TRNC as well as other places of the world highlights the importance of pre-emptive cautions by which preparedness and capabilities of the society are ready before the disaster taking place. Preemptive actions are prerequisite for the success of struggle against disasters.

\section{COMPONENTS OF THE PROJECT}

The subject of this article, "Disaster Resilient Society with Youth" project aims to contribute both the mitigation and preparedness phases in order to build a resilient society. The project is based on education and training of youth in in 
university together with others those who are between the ages of 18 and 40, with the principle of voluntarism, about disaster management, disaster risk reduction concept, TRNC disaster management system, disaster psychology, first aid and search and rescue activities. This project as pre-emptive cautions would fulfill a big deficit in the disaster management system that caused big economic damages in previous 1995 fire and 2010 flood. The contribution of the project, by increasing the mitigation and preparedness of Turkish Cypriot Youth, will be so much in terms of applying the experienced learned from the lessons of 1995 Fire and floods.

\subsection{Aims and Stakeholders of the Project}

"Disaster Resilient Society with Youth" project is prepared by the TRNC Civil Defence Organization with the following aims;

1. To create disaster consciousness among students in secondary, high schools and universities,

2. To inform them about activities before, during and after a disaster,

3. To share developments on disaster risks reduction around the world in light of global changes and improvements,

4. To share information about International Search and Rescue Advisory Group (INSARAG),

5. To integrate youth through social environments to be formed,

6. To ensure correct behavior during disaster and emergency among youth,

7. To improve the information by making individual and team applications together with the information gained and

8. To create "Disaster Resilient Society" composed of "Disaster Resilient Individuals".

As it can be observed in aims of the project defined above, the project seeks to take cautions pre-emptively without waiting the disaster to come and destroy. It is based on education and training of youth on the basis of components of disaster management and its phases. The main target of the project is defined as community and youth in order to affect future positively in terms of resilience. Research studies demonstrate that without involving social participation it is impossible to extend help to most vulnerable communities by determining the most disadvantaged groups (İstanbul Valiliği, İstanbul AFAD, İSMEP 2014).

On the other hand, to make the project more effective and to reach all levels of the society, several stakeholders have been chosen such as Ministry of National Education and Culture, District Governorships, Department of Sport, and Nongovernmental Organizations. Central coordination of the project will be carried out by the unit appointed by the Ministry of Education and Culture and Civil Defence Organization. Moreover, coordination on district level will be carried out by District Directorates of Civil Defence Organization together with school administrations, youth centres, sports clubs and non-governmental organizations.

\subsection{Code of Conduct}

The project will be announced to schools by Ministry of Education and Culture as well as by Department of Sports and Department of Youth to other collocutors. After applications of willing students, they will be trained both in theoretical and practical trainings. The theoretical part of the training consists of following topics:

1. Presentation of Civil Defence Organization and its duties,

2. Subsistence services during disaster and emergencies,

3. Basic disaster consciousness,

4. Disaster risks reduction concept and developments around the world,

5. Disaster management system of the TRNC,

6. International Search and Rescue Advisory Group (INSARAG) and its methodology,

7. Disaster Psychology,

8. First aid,

9. Fire safety and training,

10. Rope usage, knots and reels,

11. Orienteering,

12. Search and rescue equipments,

13. Right behavior before, during and after an earthquake, basic search and rescue education in earthquakes,

14. Responding to traffic accidents,

15. Concrete block dragging.

The theoretical part of the training is planned to be implemented as branch activity during afternoon times and at the education centers that will be determined in every district. After fulfillment of the theoretical part of the trainings, students and other participants will practice the project by attending to a training camp envisaged in project. During training camps, participants will find the opportunity to practice subjects taught during theoretical courses. Due to the necessity of physical capability during activities in planned training camp, a health report will be requested from all participants before they attend to the camp.

At the end of the training camp, "Certificate of Disaster Resilient Individual" as well as a badge will be issued to those who complete all training program successfully. In addition, symbolic cash prizes are planned to be distributed in order to promote motivation of the youth and encourage them to participate to the project.

\subsection{Expected Outcome}

As a beginning, for the first three years, it is intended to train one thousand young people with disaster awareness to promote the sole aim to have a more resilient society. Considering the targeted age group, the project not only aims disaster risk reduction today, but also has a vision for future to have a sustainable structure in disaster management cycle in TRNC. The project will fulfill a big gap in the disaster management system by engaging pre-emptive cautions that aims to increase the public awareness and capabilities to resist against disasters. The past experiences of 1995 big fire and flood disasters in , 2010, 2015 and 2016 tells that being prepared to disasters is important as how to react them. Another important aspect of the project is that it seeks to decentralize the struggle against the disaster. In other words, the struggle will shift form the central authorities to widespread public based on voluntary participation.

\section{CONCLUSION}

Formation of a disaster resilient society is a process in which youth cannot be ignored. The young generation in country, is a 
big potential for future in terms of prospective disaster managers or first responders. That's why "Disaster Resilient Society with Youth" project has the motto of "We Are the Future". In any way, it should not be forgotten that every individual in a society may become a victim after a possible disaster. If at least one person in every house or street has enough consciousness about disasters and emergencies, it would be positive element for response during an emergency. Moreover, experiences such as 1995 Beşparmak fire and 2010 Güzelyurt flood showed us that focusing only response phase of disaster management cycle, only gives us opportunity to be prepared to intervene a disaster. But considering modern and integrated disaster management system, as Disaster and Emergency Management Committee is based on, minimizes negative effects of disasters and reduces risks in a country. As a key institution on disaster management and response in TRNC, Civil Defence Organization is aware of its mission on creation and promotion of a disaster resilient society besides responding a disaster. In line with its mission, Civil Defence Organization seeks to implement this project with the aims of extending the cautions from being only reactive to pre-emptive as well as extending the struggle from being only state centric to widespread within the society.

\section{REFERENCES}

Ali Küçükosmanoğlu, Hamit Ayberk. "Kuzey Kıbrıs Türk Cumhuriyeti Büyük Orman Yangınları." Istanbul Üniversitesi Orman Fakültesi Dergisi 53, no. 2 (2003).

H.Kawase. "Studies on the 2011 Off the Pacific Coast of Tohoku Earthquake.” DPRI Reports, 2014: 1-2.

İstanbul Valiliği, İstanbul İl Afet ve Acil Durum Müdürlüğü, İstanbul Proje Koordinasyon Birimi. Toplumsal Kapasitenin Geliştirilmesi ve Toplum Eğitimleri. İstanbul: İSPEM Yayınları, 2014.

JICA. Disaster Resilient Society for All. Japan International Cooperation Agency, 2017.

Kadığlu, Mikdat. Afet Yönetimi, Beklenilmeyeni Beklemek, En Kötüsünü Yönetmek. İstanbul: T.C. Marmara Belediyeler Birliği, 2011.

Macao Meteorological and Geophysical Bureau. 2014. http://www.smg.gov.mo/smg/geophysics/e_sis_f\&q.htm (accessed 2 12, 2018).

TRNC Council of Ministers. "H(K-I)684-2016.” Lefkoşa, 11 August 2016.

UN/ISDR. Geneva, 2004.

UNISDR. "Sendai Framework for Action." PreventionWeb. 2015.

https://www.preventionweb.net/files/43291_sendaiframeworkfo rdrren.pdf (accessed January 18, 2018). 